\title{
Progeroid Syndrome of De Barsy With Hypocalcemic Seizures
}

\author{
Cheriathu J', D'souza IE², John LJ33, Bahtimi RE \\ ${ }^{1}$ Dr. Jenny Cheriathu, DNB Department of Pediatrics, Gulf Medical College Hospital, Ajman, UAE, ${ }^{2}$ Dr. Ignatius Edwin \\ D'souza, MD, Department of Pediatrics, Gulf Medical College Hospital, Ajman, UAE, ${ }^{3}$ Dr. Lisha J John, MD, Department of \\ Pharmacology, Gulf Medical University, Ajman, UAE, ${ }^{4}$ Dr. Reem El Bahtimi, MD, Consultant Dermatopathologist, American \\ Hospital, Dubai, UAE.
}

Address for correspondence: Dr. Jenny Cheriathu, Email: jennyjohnc@yahoo.co.in

\begin{abstract}
De Barsy et al first reported a rare cutaneo-oculo-cerebral malformation-syndrome now commonly referred as 'progerioid syndrome of de Barsy'. It is the constellation of progeria-like appearance, cutis laxa, intrauterine growth retardation, corneal clouding and hypotonia. We report a case of Debarsy syndrome in a neonate presented at birth with typical clinical features with hypocalcemic seizures. There are no previous reports among Afghani origin and also first case reported from United Arab Emirates, there have been no reported cases of hypocalcemic seizures.
\end{abstract}

Key words: De Barsy, Progeroid syndrome, Cutis laxa

\section{Introduction}

$\mathrm{D}$ Barsy et al first reported a rare cutaneo-oculocerebral malformation-syndrome now commonly referred as 'progerioid syndrome of de Barsy' ${ }^{\prime}$. It is a rare, autosomal recessive syndrome with a constellation of progeria-like appearance, cutis laxa, intrauterine growth retardation, corneal clouding and hypotonia. Approximately 28 further cases have been reported worldwide. We report a case of De Barsy syndrome in a neonate presented at birth with typical clinical and histological features.

\section{The Case}

A newborn male child was born by Caesarian section, the fifth child born to non-consanguineous Afghani couple, mother aged 32 years and father 36 years. All the other siblings are alive and well, with normal growth and development, without any dysmorphism.

The baby was noted to have poor tone and weak suck. On general examination, the neonate had an aged facial appearance, which was most striking; with wide open anterior fontanelle. The baby was also noted to have hypertelorism with corneal clouding, small upturned nose, small mouth, thin lips, relatively large ears and thin hair (Figure 1). In addition, he had a lax, wrinkled skin (Figure 2), especially in the neck, axillae, gluteal region and lower limbs and a congenital hydrocoele with hidden penis. The skin was dry and translucent with visible blood vessels. Neurological examination revealed significant hypotonia with head lag, weak primitive reflexes (Moro, rooting and sucking reflex), hyperextensible joints and positive scarf sign. Anthropometry was suggestive of symmetrical intrauterine growth retardation (Head circumference- $32 \mathrm{cms}$, length- 50 $\mathrm{cms}$, birth weight- $2.42 \mathrm{kgs}$ and Ponderal Index- 1.92).

Baby was initially started on naso-gastric feeds and could tolerate oral feeds only by the sixth day of life; however cry and activity continued to remain poor.

At 6 weeks of life, he presented with generalized tonic-clonic seizures for which he was started on injection phenobarbitone. Septic work-up was unremarkable. Other laboratory investigations were within normal limits except for low serum albumin levels (2.12 g/dL) and low serum calcium (4.8mg/dL). CT scan done did not reveal any intracranial bleeds or other gross structural abnormalities.

With the consent of the parents, lumbar puncture, karyotyping and skin biopsy were performed. The lumbar puncture and karyotyping reports were normal. The histochemical study of skin biopsy showed complete absence of elastic fibres within the papillary and reticular 
dermis (Verhoeff Van Gieson stain) which confirmed the diagnosis of cuits laxa (Fig 3). Follow-up at 10 weeks of life showed complete head lag with no social smile.

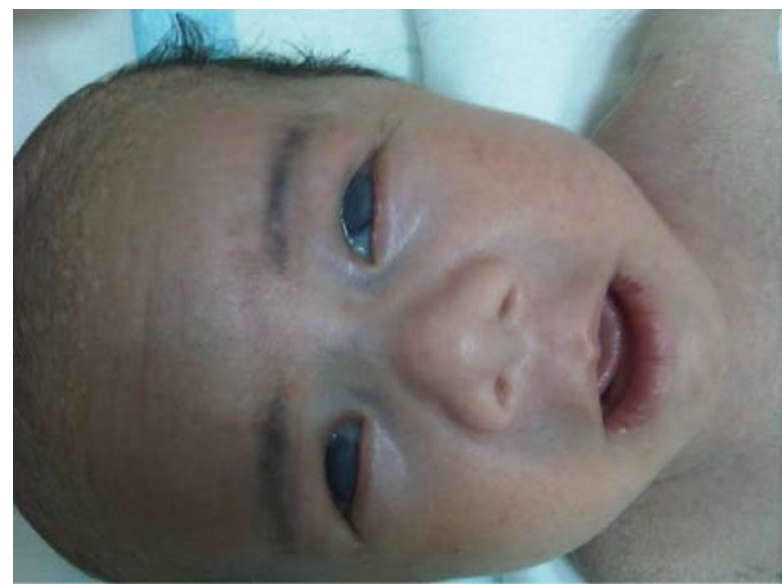

Fig 1: Strikingly old looking face, hypertelorism with cloudy cornea, small up-turned nose, small mouth, thin lips.

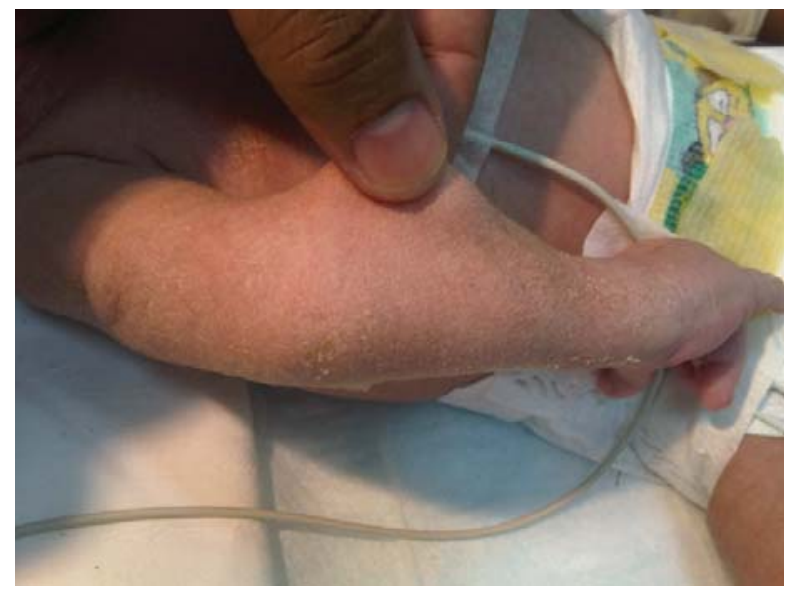

Fig 2: Dry skin with cutis laxa.

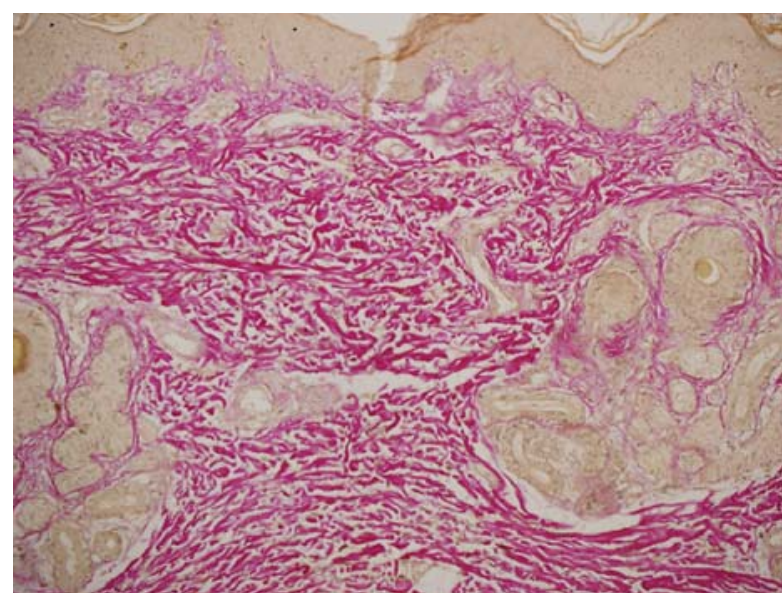

Fig 3: Verhoeff- Van Gieson stained sections from skin shows loss of fine elastic fibres in papillary dermis and decrease in fibres in dermis and shortening of fibres noted. Mononuclear infiltrate is noted.

\section{Discussion}

The main features of the present case include peculiar old looking face, corneal clouding, muscular hypotonia, cutis laxa and intra-uterine growth retardation. These findings are suggestive of De Barsy syndrome which hitherto has been reported in the previous case reports.

In 1968, De Barsy et al, ${ }^{1}$ first described the syndrome in a 22 month old girl born to non-consanguineous parents, with features of cutis laxa, corneal clouding and psychomotor retardation. Sporadic cases with similar findings were reported by Haefnagel et al, Burck, Pontz et al and Morris at el $\mathrm{l}^{2-5}$. Kivuva et al reported a case with similar features in a child of second degree consanguineous parents of Pakistani origin ${ }^{6}$. They also systematically reviewed earlier reported 27 cases of De Barsy syndrome. Riebel et al and Kunze et al described multiple affected siblings which suggested the possibility of a genetic disorder ${ }^{7,8}$. Later, Pontz et al and Kivuva et al suggested an autosomal recessive inheritance, although karyotypic abnormalities or genetic linkages could not be ascertained ${ }^{4,6}$.

The case described by Pontz et $\mathrm{al}^{4}$ also described fraying of elastin fibers with decreased number and density ${ }^{4}$. Karnes et al had performed elastin gene study on the fibroblasts cultured from the skin and found reduced steady-state levels of elastin mRNA, suggesting reduced elastin synthesis ${ }^{9}$. The clinical characteristics of the present case when compared to the earlier reported cases showed the following features as shown in the Table-1 ${ }^{1-9}$.

The present baby was among the youngest reported cases of De Barsy syndrome. This was a sporadic case with no other family members with similar features. There have been no case reports from the Middle East countries. The baby had in addition a congenital hydrocoele which probably would be due to the loss of subcutaneous fat and hypoalbuminemia. The hypoalbuminemia could probably be due to a decreased synthesis of proteins or excessive catabolism of these. Baby presented with hypocalcemic seizures which has not been reported in previous literature. Certain features like athetosis, grimacing were not noted in the baby probably as the baby is only three months old at his last visit and would require regular follow-up, although the possibility is high as baby continues to have no head control with significant hypotonia. Some signs of the de Barsy syndrome are also observed in Geroderma osteodysplasticum/gerodermia osteodysplastica, Hutchinson-Gilford Progeria Syndrome, neonatal progerioid syndrome, Hallerman-Streiff syndrome and the cutis laxa syndromes. All these syndromes can be differentiated by characteristic, phenotypic differences. 
Table 1: Clinical characteristics of the present case versus earlier cases (28 cases).

\begin{tabular}{|c|c|c|c|}
\hline Clinical Characteristics & Present Study & Ear & tudies* \\
\hline Progerioid/aged appearance & + & 23 & $(79 \%)$ \\
\hline Prominent forehead & + & 20 & $(69 \%)$ \\
\hline Large fontanelles & + & 15 & $(52 \%)$ \\
\hline Large, low-set, dysplastic ears & + & 23 & $(79 \%)$ \\
\hline Thin lips, small mouth & + & 13 & $(45 \%)$ \\
\hline Small nose, upturned & + & 10 & $(34 \%)$ \\
\hline Sparse hair & + & 8 & $(28 \%)$ \\
\hline Hypotonia & + & 21 & $(72 \%)$ \\
\hline Athetoid movements & - & 13 & $(45 \%)$ \\
\hline Grimacing & - & 10 & $(34 \%)$ \\
\hline Seizures/abnormal EE & + & 9 & $(31 \%)$ \\
\hline IUGR & + & 25 & $(96 \%)$ \\
\hline $\begin{array}{l}\text { Cutis laxa } \\
\text { Thin translucent skin } \\
\text { Reduced subcutaneous fat }\end{array}$ & $\begin{array}{l}+ \\
+ \\
+\end{array}$ & 28 & $(100 \%)$ \\
\hline Inguinal, umbilical hernias & - & 10 & $(34 \%)$ \\
\hline Corneal opacification & + & 14 & $(48 \%)$ \\
\hline Cataracts & - & 8 & $(28 \%)$ \\
\hline Myopia & - & 6 & $(21 \%)$ \\
\hline Strabismus & - & 5 & $(17 \%)$ \\
\hline Blue sclerae & + & 3 & $(10 \%)$ \\
\hline Hyperextensible joints & + & 16 & $(55 \%)$ \\
\hline Clenched hands/adducted thumbs & - & 15 & $(52 \%)$ \\
\hline Congenital hip dislocation & - & 12 & $(41 \%)$ \\
\hline Pectus excavatum & - & 10 & (34\%) \\
\hline Delayed bone age & - & 6 & $(21 \%)$ \\
\hline Talipes and scoliosis & - & 5 & $(17 \%)$ \\
\hline
\end{tabular}

This manuscript was presentated on $24^{\text {th }}$ June 2011, during the $5^{\text {th }}$ Europediatrics Congress $\left(23-26^{\text {th }}\right.$ June 2011), Vienna, Austria.

\section{References}

1. De Barsy AM, Moens E, Dierckx L. Dwarfism, oligophrenia and degeneration of the elastic tissue in skin and cornea. A new syndrome? Helv Paediat Acta 1968;23:305-13.

2. Hoefnagel D, Pomeroy J, Wurster D, Saxon A. Congenital athetosis, mental deficiency, dwarfism and laxity of skin and ligaments. Helv Paediat Acta 1971;26:397-402.

3. Burck U. De Barsy-Syndrom--eine weitere Beobachtung. Klin Paediatr 1974;186:441-44.

4. PontzBF,ZeppF, Stoss H. Biochemical, morphological and immunological findings in a patient with a

\section{How to cite this article?}

Cheriathu J, D'souza IE, John LJ, Bahtimi RE. Progeroid Syndrome of De Barsy With Hypocalcemic Seizures. J Nepal Paediatr Soc 2012;32(2):175-177. cutis laxa-associated inborn disorder (De Barsy syndrome). Europ J Pediat 1986;145: 428-34.

5. Morris CA, Clark EGI. DeBarsy syndrome: differential diagnosis. Am J Hum Genet 1990;47 (suppl): A68.

6. Kivuva EC, Parker MJ, Cohen MC, Wagner BE, Sobey G. De Barsy syndrome: a review of the phenotype. Clin Dysmorph 2008;17: 99-107.

7. Riebel T. De Barsy-Moens-Dierckx-Syndrom: Beobachtung bei Geschwistern. Mschr Kinderheilk 1976;124: 96-8.

8. Kunze J, Majewski F, Montgomery P, Hockey A, Karkut I, Riebel T. De Barsy syndrome--an autosomal recessive, progeroid syndrome. Europ J Pediat 1985;144: 348-54.

9. Karnes PS, Shamban AT, Olsen DR, Fazio MJ, Falk RE. De Barsy syndrome: report of a case, literature review, and elastin gene expression studies of the skin. Am J Med Genet 1992;42:29-34. 